\title{
PATTERN AND PROFILE OF PATIENTS WITH ACNE VULGARIS
}

\author{
Geeta Sharma1, Shubhra Shukla², P. K. Dash³, Sudhir Sharma
}

${ }^{1}$ Assistant Professor, Department of Dermatology, Rama Medical College and Research Centre.

${ }^{2}$ Senior Resident, Department of Dermatology, Rama Medical College and Research Centre.

3 Professor, Department of Dermatology, Rama Medical College and Research Centre.

${ }^{4}$ Assistant Professor, Department of Dermatology, Rama Medical College and Research Centre.

ABSTRACT
BACKGROUND
Acne vulgaris is a multifactorial chronic inflammatory disease of the pilosebaceous follicles. It is believed to be the most
common disease of the skin. Both sexes are affected, but the disease tends to be more severe in males.

\section{OBJECTIVE}

The aim of our study was to assess the profile of acne vulgaris, its seasonal variation and possible correlation between it and markers of androgenicity in females.

\section{METHOD}

The study was conducted over a period of 6 months from June 2015 to November 2015. All patients with acne vulgaris attending our Outpatient Department (OPD) were included. The parameters considered include age, gender, age of onset, duration, site and type of lesions, grade, relationship with menstrual cycle, markers of androgenicity, seasonal variation and any complications. Acne vulgaris was graded using a simple grading system, which classifies acne vulgaris into four grades.

\section{RESULTS}

A total of 4362 patients were included in the study. The frequency of acne vulgaris in our study was $12.5 \%$. The male-to-female ratio was 1.4:1. The maximum number of patients belonged to the age group 16-20 years (54.1\%); 327 (60\%) patients had lesions only on the face followed by involvement of other areas like chest, arms and back. The most common type of lesions were closed comedones. A total of $41.5 \%$ patients had grade $2,27.4 \%$ had grade $1,19.5 \%$ had grade 3 and $11.6 \%$ had grade 4 . Male patients had more severe acne vulgaris; $11.1 \%$ of females gave a history of irregular menstrual periods; $12 \%$ of females had some marker of androgenicity. In $17.06 \%$ patients, summer exacerbation was seen. The most common complication was post acne hyperpigmentation (41.8\%) followed by post acne scarring.

\section{CONCLUSION}

This study brings out the clinical profile of acne vulgaris in a tertiary care hospital.

\section{KEYWORDS}

Acne Vulgaris, Comedones, Post Acne Hyperpigmentation, Post Acne Scarring.

HOW TO CITE THIS ARTICLE: Sharma G, Shukla S, Dash PK, et al. Pattern and profile of patients with acne vulgaris. J. Evolution Med. Dent. Sci. 2016;5(64):4552-4556, DOI: 10.14260/jemds/2016/1039

\section{INTRODUCTION}

Acne vulgaris is a multifactorial chronic inflammatory disease of the pilosebaceous follicle occurring predominantly on the face and trunk. It is believed to be the most common disease of the skin.1,2 for which all patients including those with skin of colour (Fitzpatrick skin types IV-VI), seek dermatological care. Acne often affects adolescents and young adults. It may persist into middle age in some patients. Both sexes are affected, but the disease tends to be more severe in males. Females with severe acne may have an associated endocrine problem. Most frequently acne occurs on the face and in the long term can produce cutaneous scarring and psychological impairment.

Financial or Other, Competing Interest: None.

Submission 02-07-2016, Peer Review 25-07-2016,

Acceptance 02-08-2016, Published 11-08-2016.

Corresponding Author:

Dr. Geeta Sharma,

Rama Medical College and Research Centre,

Mandhana, Kanpur

Uttar Pradesh,

India.

E-mail: docgeetasharma@gmail.com

DOI: $10.14260 / j e m d s / 2016 / 1039$
The aim of our study was to assess the profile of acne vulgaris, its seasonal variation and possible correlation between it and markers of androgenicity in females.

\section{METHOD}

The study was conducted over a period of 6 months from June 2015 to November 2015. All patients with acne vulgaris attending our Outpatient Department (OPD) were included. Patients with drug-induced and other acneiform eruptions were excluded. Pregnant and lactating patients were excluded. A detailed history was taken. Each patient was examined in a room with good natural light. The examination included the face, arms, back and chest areas. The parameters considered include age, gender, age of onset, duration of lesions, site of lesions, grade, relationship with menstrual cycle, markers of androgenicity, type and number of acne lesions such as comedones, papules, pustules and nodules, any complications like post-acne scarring, post-acne hyperpigmentation, hypertrophic scar and seasonal variation. Acne vulgaris was graded using a simple grading system taking into account the predominant lesion to grade acne, which classifies acne vulgaris into four grades. ${ }^{3}$ 
Grade 1: Comedones, occasional papules.

Grade 2: Papules, comedones, few pustules.

Grade 3: Predominant pustules, nodules, abscesses.

Grade 4: Mainly cysts, abscesses, widespread scarring.

\section{RESULTS}

During the 6 months study period, 4362 patients attended the Dermatology OPD. Out of these, 545 patients had acne vulgaris and the frequency was $12.5 \%$. Of the 545 patients, $225(41.3 \%)$ were females and 320 (58.7\%) were males. Male-to-female ratio was 1.4:1. The age of the patients varied from 12 to 43 years with the mean of 20.4 years ( $S D \pm 4.2$ ). In the present study, maximum number of patients belonged to the age group 16-20 years (295 cases, $54.1 \%$ ), followed by 21 - 25 years (106 cases, 19.4\%). Prevalence of acne vulgaris according to age and sex in our study is detailed in Table 1.

The duration of acne varied from minimum of 2 weeks to as long as 26 years; $138(25.3 \%)$ patients had duration of lesions < 1 year, $226(41.5 \%)$ patients had duration between 1-2 years, $99(18.2 \%)$ patients had duration between 3-4 years, whereas only $82(15.0 \%)$ had duration more than 4 years as shown in Table 2 . It was also noted that patients with longer duration of the disease had more severe acne vulgaris.

Out of 545 patients, 327 (60\%) patients had lesions only on the face, $89(16.3 \%)$ patients had lesions on face, back and chest, 75 (13.8\%) patients had lesions on face and back, 32 (5.9\%) had lesions on face and chest, 22 (4\%) patients had lesions on back, chest and arm. The type of lesions in this study was closed comedones (which were most common), open comedones (2nd most common) followed by papules, pustules and nodulocysts.

Majority of the patients were having acne grade 2 (41.5\%) followed by grade $1(27.4 \%)$, grade $3(19.5 \%)$ and grade $4(11.6 \%)$ [Figure 1-4]. In our study, we found that acne was more severe among the patients aged 20 years or older. It was also found that male patients had more severe acne vulgaris (55 males vs. 9 females had grade 4 acne vulgaris) as shown in Figure 5.

In our study the aggravating factors were premenstrual flare $(65.8 \%)$, summer season $(28.4 \%)$, sun exposure $(23 \%)$, fatty and fried food (18.9\%) and winter season (5.9\%). Out of 225 females, 25 female patients (11.1\%) gave a history of irregular menstrual periods. A history of premenstrual flare was reported by 141 (62.7\%) female patients; 27 patients $(12 \%)$ had some marker of androgenicity, commonest being hirsutism which was present in 14 patients and others were androgenic alopecia and acanthosis nigricans.

Seasonal variation was observed only in 118 patients (21.6\%); 155 patients (28.4\%) gave history of acne exacerbation during summers and 32 patients (5.9\%) in winter.

The most common complication was post acne hyperpigmentation (Figure 6), which was seen in 228 patients $(41.8 \%)$. This was followed by post-acne scarring (Figure 7), which was seen in 194 patients (35.6\%). Cheeks were the most common site of post-acne scarring. Ice-pick scars were the most common type of scars. Patients with longer duration of the disease are more likely to have postacne scarring.

\begin{tabular}{|c|c|c|c|}
\hline \multirow{2}{*}{$\begin{array}{c}\text { Age } \\
\text { (In Yrs.) }\end{array}$} & Male & Female & \multirow{2}{*}{ Total (\%) } \\
\cline { 2 - 4 } 10-15 Yrs. & 39 & 22 & $61(11.2 \%)$ \\
\hline $16-20$ Yrs. & 176 & 119 & $295(54.1 \%)$ \\
\hline $21-25$ Yrs. & 66 & 40 & $106(19.4 \%)$ \\
\hline $26-30$ Yrs. & 34 & 17 & $51(9.3 \%)$ \\
\hline$>30$ Yrs. & 5 & 27 & $32(5.9 \%)$ \\
\hline Total & $\mathbf{3 2 0}(\mathbf{5 8 . 7} \%)$ & $\mathbf{2 2 5}(41.3 \%)$ & $\mathbf{5 4 5}$ \\
\hline Table 1: Prevalence of Acne According to Age \& Sex \\
\hline
\end{tabular}

\begin{tabular}{|c|c|c|}
\hline Duration & No. of Cases & Percentage (\%) \\
\hline < 1 Yrs. & 138 & $25 \%$ \\
\hline 1 - 2 Yrs. & 226 & $41.50 \%$ \\
\hline 3 - 4 Yrs. & 99 & $18.20 \%$ \\
\hline > Yrs. & 82 & $15.00 \%$ \\
\hline Total & $\mathbf{5 4 5}$ & $\mathbf{1 0 0 \%}$ \\
\hline \multicolumn{2}{|c|}{ Table 2: Distribution of Cases According } \\
to Duration of Acne \\
\hline
\end{tabular}

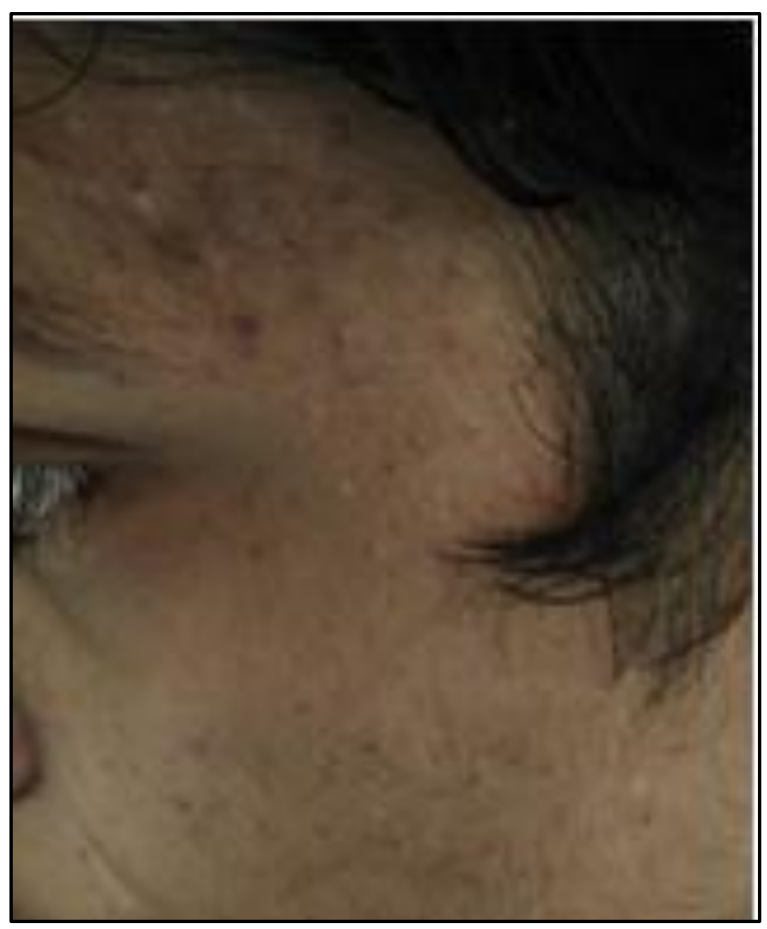

Fig. 1: Showing Grade 1 Acne Vulgaris

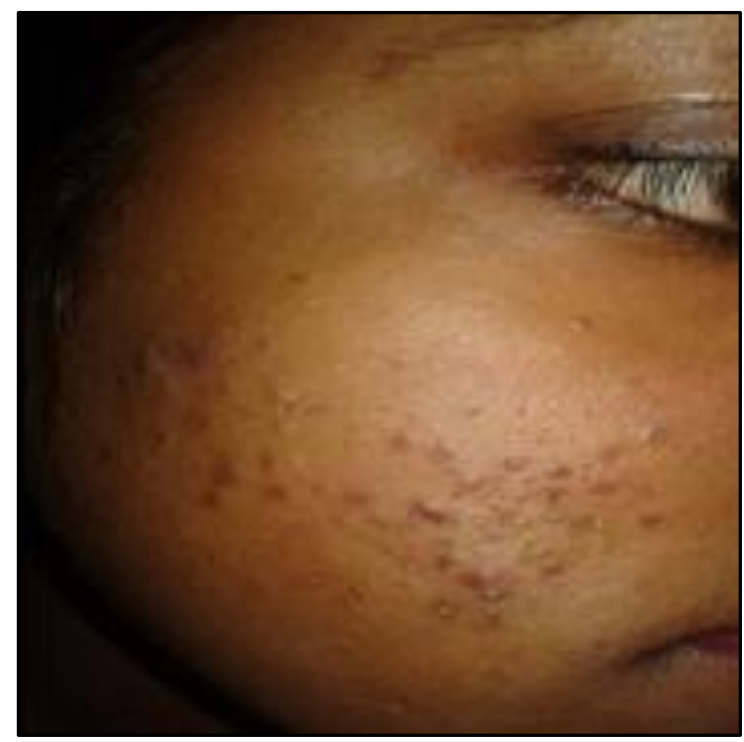

Fig. 2: Showing Grade 2 Acne Vulgaris 


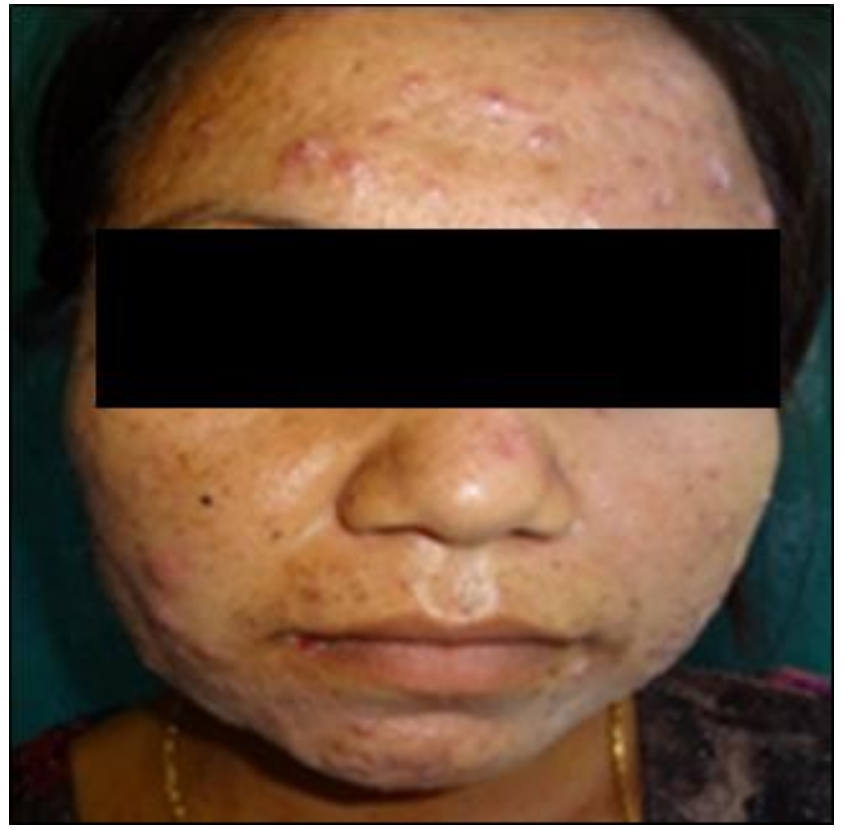

Fig. 3: Showing Grade 3 Acne Vulgaris

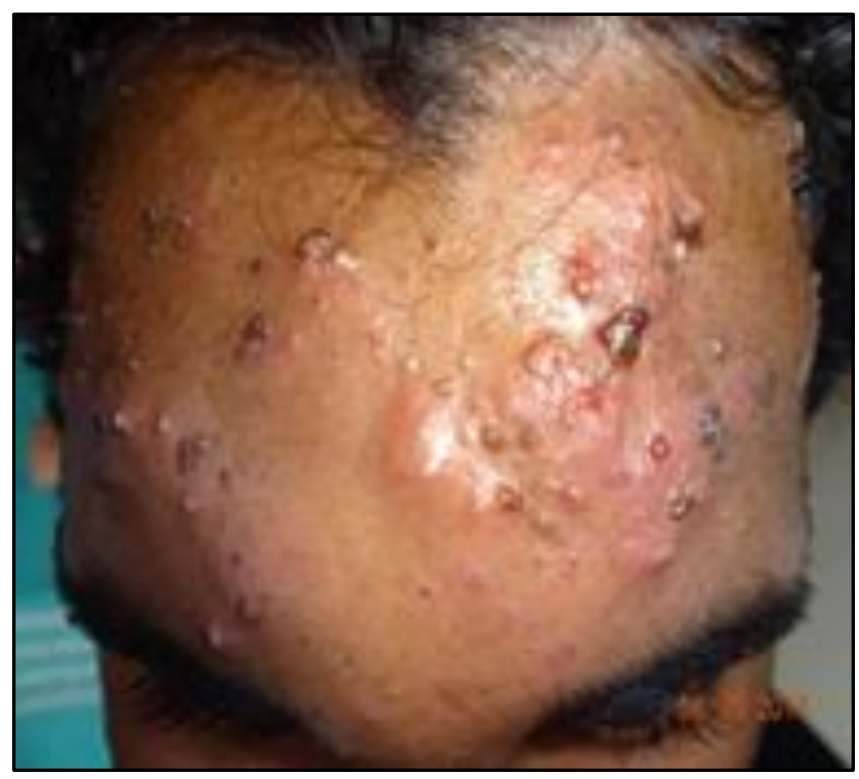

Fig. 4: Showing Grade 4 Acne Vulgaris

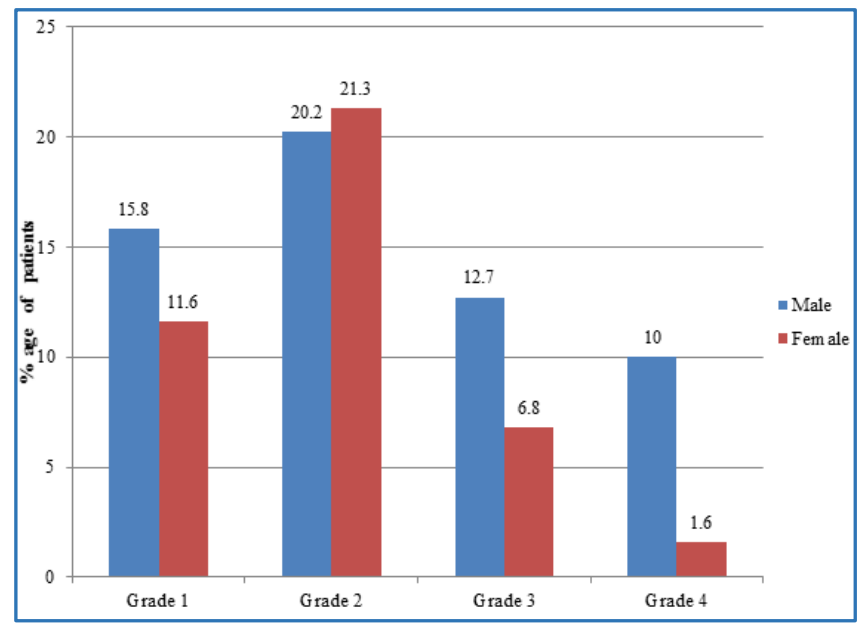

Fig. 5: Severity According to Grade of Acne

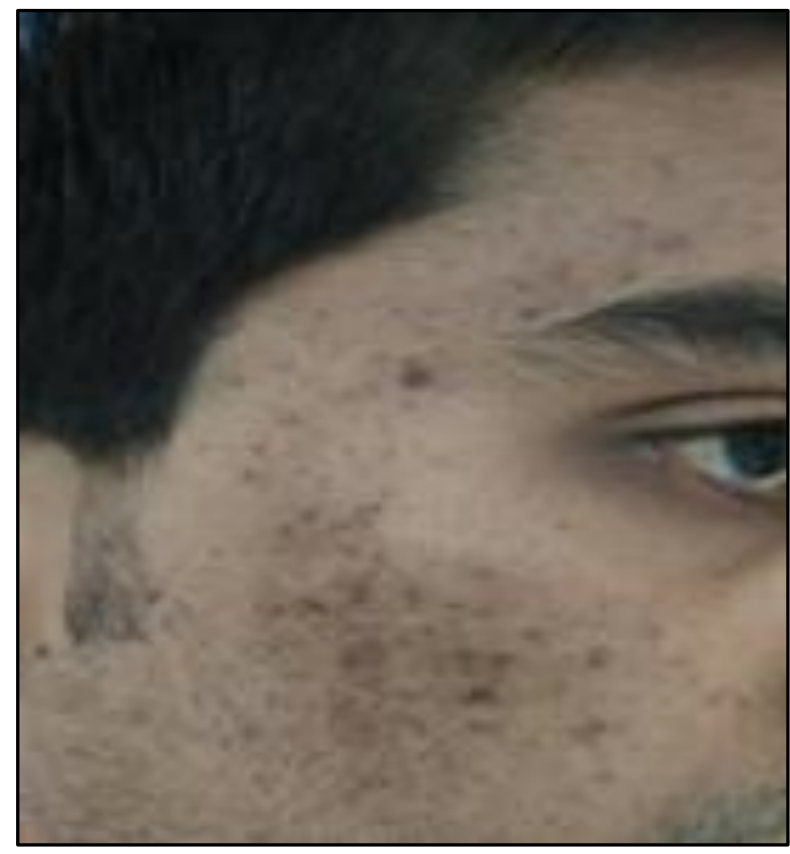

Fig. 6: Showing Post Acne Hyperpigmentation

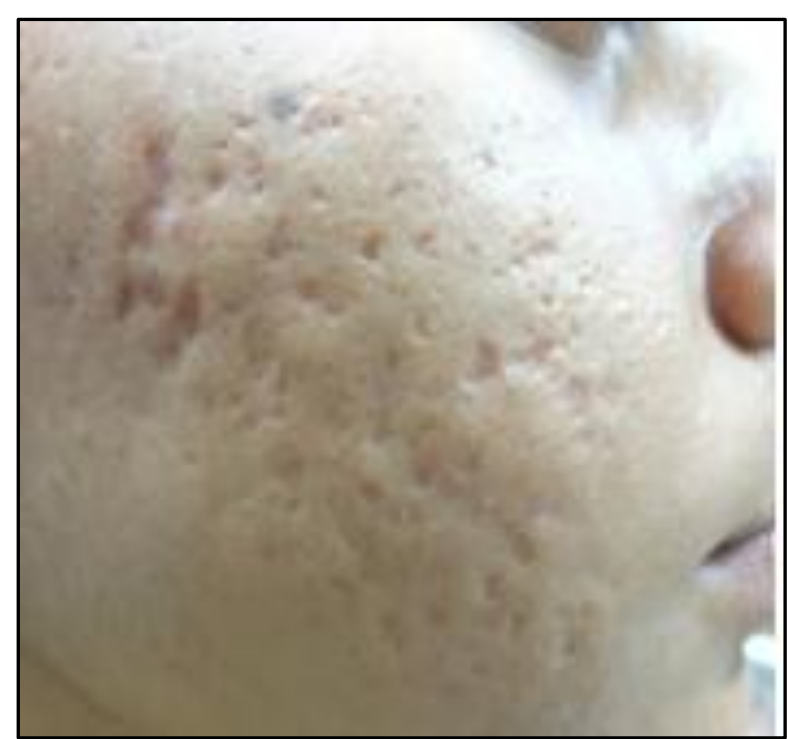

Fig. 7: Showing Post Acne Scarring

\section{DISCUSSION}

Acne is one of the most common skin disorders worldwide and occurs primarily at puberty with a prevalence of almost $95 \% .{ }^{4}$ In our study, acne vulgaris accounted for $12.5 \%$ of the total number of patients examined in our centre. It was similar to other hospital-based studies done on acne vulgaris in Asian population, in which acne vulgaris constitutes $11.2 \%$ and $19.6 \%$ of the total new patients attending their hospitals.5,6 A survey of Australian private dermatology practices reported that of 3197 new diagnoses, 320 (10\%) patients were for acne. ${ }^{7}$ But in a study by Adityan B and Thappa $\mathrm{DM}, 8$ acne vulgaris accounted for only $1.06 \%$ of the total number of new patients. In their study they explained the low frequency due to a low prevalence of acne vulgaris among South Indian population.

Acne vulgaris develops earlier in females than in males. ${ }^{1,2,5}$ The earlier onset of clinical acne in girls than boys is presumably related to their earlier puberty. In a study by $\mathrm{Al}$-Ameer and Al-Akloby, ${ }^{5}$ the age at presentation was 
$19.2 \pm 3.0$ years for males and $18.4 \pm 4.2$ years for females. Kane et $\mathrm{al}^{9}$ noted that the mean age of presentation of their patients was 25.58 years, whereas Adityan B and Thappa DM. ${ }^{8}$ found in their study that the mean age of patients was 19.78 years $(S D \pm 4.94)$. The mean age of patients in our study population was 20.4 years ( $\mathrm{SD} \pm 4.2$ ), which is similar to other studies mentioned.

It was seen in earlier studies that in adolescent age group males tend to show the most severe forms of the disease, whereas adult acne is more common in females. ${ }^{10,11,12,13}$ In our study also we found that in the older age group, women were more affected by acne vulgaris than men. Hormonal factors, increased use of cosmetics and exposure to hot and humid conditions while cooking may play a role in increased prevalence of adult acne in women. In accordance with earlier studies, 8,14,15 it was found in our study also that severe acne occurred commonly in patients of older age group.

In our study $138(25.3 \%)$ patients had duration of lesions $<1$ year, $226(41.5 \%)$ patients had duration between 1-2 years, $99(18.2 \%)$ patients had duration between 3-4 years, whereas only $82(15.0 \%)$ had duration more than 4 years. Tan et al 16 in their study of 78 patients observed that $74 \%$ of patients had a duration of more than 1 year before seeking medical attention, $12 \%$ had between 6-12 months, $6 \%$ had between 3-6 months and 7\% had a duration less than 3 months.

Acne vulgaris occurs in sites, which are rich in pilosebaceous units. In the present study out of 545 patients $327(60 \%)$ patients had lesions only on the face; $89(16.3 \%)$ patients had lesions on face, back and chest; 75 (13.8\%) patients had lesions on face and back; 32 (5.9\%) had lesions on face and chest; 22 (4\%) patients had lesions on back, chest and arm. In a study by Biswas et al, ${ }^{17}$ out of 400 patients the majority had acne only on face, while face along with other areas such as chest and shoulder comprised the second largest group (18\%). Adityan B and Thappa $\mathrm{DM}^{8}$ found in their study that face was the theatre of action in all the patients with acne vulgaris (100\%), back was involved in $28.2 \%$, chest was involved in $20.1 \%$, neck was involved in $9.4 \%$ and arms were involved in $10 \%$.

Acne shows a variable and fluctuating mix of comedones, folliculocentric inflammatory lesions, scars and pigmentary disturbances. The full spectrum includes many types of comedones - blackheads (Open comedones), whiteheads (Closed comedones), missed comedones, macrocomedones, sandpaper comedones, submarine comedones ${ }^{18}$; inflammatory lesions - papules, pustules, nodules, cysts, macules; atrophic scars - rolling, boxcar, ice-pick; hypertrophic scars and keloids; and Acne Hyperpigmented Macules (AHM). ${ }^{19}$ The preadolescent acne and the beginning of adolescent acne is largely comedonal. ${ }^{20}$ In our study, we graded the severity of acne vulgaris using a simple and quick system of classification using a four-grade system. ${ }^{3}$ The most common type of lesion in our group of acne patients was closed comedones. Majority of our patients were having acne grade $2(41.5 \%)$ followed by grade 1 (27.4\%), grade 3 (19.5\%) and grade 4 (11.6\%). In the study by Adityan B and Thappa DM,8 grade 1 acne vulgaris was most common and similar findings was noticed by Kane et $\mathrm{al}^{9}$; however, the lesions were mainly comedones. Kilkenny et al ${ }^{14}$ and Cunliffe et $\mathrm{al}^{18}$ reported that comedones were the most common type of lesion.
Acne is said to be typically vacillating in its course ${ }^{21}$; various triggers and aggravating factors have been identified, which may be accountable for periodic flares. Increasing pubertal age, seborrhoea, the premenstrual phase, mental stress and sweet and oily foods have been reported as risk factors for moderate-to-severe acne.22 In our study the aggravating factors were premenstrual flare $(62.7 \%)$, summer season $(28.4 \%)$, sun exposure (23\%), fatty and fried food (18.9\%) and winter season (5.9\%).

Premenstrual flare was noticed in $62.7 \%$ of the 225 female patients in our study. Williams and Cunliffe ${ }^{23}$ have stated that acne worsens premenstrually in $60-70 \%$ of females. Shaw ${ }^{24}$ reported a $27 \%$ rate of premenstrual acne flare in a sample of 85 women. In the study of Stoll et al, 25 $44 \%$ of 400 female participants reported premenstrual flares of their acne in the questionnaires. Although, there is a hypothesis about changes of surface lipid composition in the premenstrual phase, changes in hydration or the molecular structure of keratins ${ }^{26}$ or prostaglandin effects through its vasoactive properties. 27 The exact hormonal cause for this flare is still to be elucidated.

In our study, $12 \%$ patients had some markers of androgenicity. The most common marker of androgenicity observed was hirsutism present in 14 patients; 25 female patients $(11.1 \%)$ gave a history of irregular menstrual periods. The other features of androgenicity were female pattern androgenic alopecia and acanthosis nigricans. The incidence of hirsutism and irregular menses observed in earlier studies. ${ }^{28,29,30}$ varied between $0 \%$ to $21 \%$ and $15.5 \%$ to $48 \%$, respectively.

Summer season and sun exposure act as aggravating factors in $28.4 \%$ and $23 \%$ of patients respectively in our study. In an Indian study in $80.62 \%$ patients, summer aggravation of acne was seen. ${ }^{23}$ It is possible that UV radiation, which may cause inflammation and generate squalene peroxides which are highly comedogenic may play a role in the persistence of acne in tropical countries in addition to sweating and increased humidity.24,25 On the other hand, winter season aggravates acne in only $5.9 \%$ patients in our study. Like ours, Adityan B and Thappa DM ${ }^{8}$ found in their study that seasonal variation was observed only in 80 patients $(25.9 \%) ; 71$ patients $(23 \%)$ exacerbated in summer and $9(2.9 \%)$ in winter. This observation was against the conventional view that acne vulgaris exacerbates in winter and improves in summer.

In our study, $18.9 \%$ patients gave history of acne aggravation on intake of fatty and fried foods. A high glycaemic diet induces hyperinsulinemia which results in androgen synthesis, similar to Polycystic Ovarian Disease (PCOD). ${ }^{31}$ Diet induced hyperinsulinemia also increases level of IGF-1 (Insulin-Like Growth Factor) and reduces IGF binding proteins. The increased free IGF-1 level results in unregulated growth of follicular epithelium, increased sebum production and synthesis of androgens from gonads. ${ }^{31}$

In our study, the most common complication was post acne hyperpigmentation in 228 patients (41.8\%), followed by post acne scarring in 194 patients (35.6\%). Inflammatory lesions in acne promote the development of PostInflammatory Hyperpigmentation (PIH), scarring and keloids. Taylor et $\mathrm{al}^{32}$ found acne hyperpigmented macules present in 65.3 percent of African-American, 52.7 percent of Hispanic, and 47.4 percent of Asian patients with acne. Similar to our study, $\mathrm{T}$ Kane et $\mathrm{al}^{9}$ noticed a high incidence $(40.2 \%)$ of post- 
acne scarring in patients. We also observed that post-acne scarring was more likely in patients with longer duration of the disease.

This is an expected finding, which is also reported in earlier studies.12,32 The ice-pick scars were the most common type of post-acne scars. Keloid formation and hypertrophic scarring are other sequelae of acne more commonly seen in the skin of colour population.

\section{CONCLUSION}

This study brings out the clinical profile of acne vulgaris in a tertiary care hospital. It revealed a high prevalence of acne in adolescents with a higher prevalence of the comedonal form. The community prevalence of acne is much higher than the prevalence recorded in this study. It is probable that not all teenagers who could benefit are accessing health care services for acne treatment. Further education about acne is necessary in schools and among the public, so that one knows where to seek appropriate advice and receive early effective treatment so as to prevent complications.

\section{REFERENCES}

1. Gelmetti CC, Krowchuk DP, Lucky AW. Acne. In: Schachner LA, Katz SI, eds. Pediatric dermatology. $3^{\text {rd }}$ edn. Philadelphia: Mosby 2003:589-609.

2. Kerkemeyer K. Acne vulgaris. Plast Surg Nursing 2005;25:31-5.

3. Tutakne MA, Chari KV. Acne, rosacea and perioral dermatitis. In: Valia RG, Valia AR, eds. IADVL Textbook and atlas of dermatology. $2^{\text {nd }}$ edn. Mumbai: Bhalani 2003:689-710.

4. Burton JL, Cunliffe WJ, Stafford I, et al. The prevalence of acne vulgaris in adolescence. $\mathrm{Br} \mathrm{J}$ Dermatol 1971;85(2):119-26.

5. Al-Ameer AM, Al-Akloby OM. Demographic features and seasonal variations in patients with acne vulgaris in Saudi Arabia: a hospital-based study. Int J Dermatol 2002;41(12):870-1.

6. Tan HH, Tan AW, Barkham T, et al. Community based study of acne vulgaris in adolescents in Singapore. $\mathrm{Br} \mathrm{J}$ Dermatol 2007;157:547-51.

7. Stathakis V, Kilkenny M, Marks R. Descriptive epidemiology of acne vulgaris in the community. Australas J Dermatol 1997;38(3):115-23.

8. Adityan B, Thappa DM. Profile of acne vulgaris-a hospitalbased study from south India. Indian J Dermatol Venereol Leprol 2009;75(3):272-8.

9. Kane A, Niang SO, Diagne AC, et al. Epidemiological, clinical, and therapeutic features of acne in Dakar, Senegal. Int J Dermatol 2007;46(Suppl 1):36-8.

10. Goulden V, Clark SM, Cunliffe WJ. Post-adolescent acne: a review of clinical features. Br J Dermatol 1997;136(1): 66-70.

11. Williams C, Layton AM. Persistent acne in women. Implications for the patient and for therapy. Am J Clin Dermatol 2006;7(5):281-90.

12. Goulden V, Stables GI, Cunliffe WJ. Prevalence of facial acne in adults. J Am Acad Dermatol 1999;41(4):577-80.

13. Shaw JC, White LE. Persistent acne in adult women. Arch Dermatol 2001;13(7):1252-3.
14. Kilkenny M, Merlin K, Plunkett A, et al. The prevalence of common skin conditions in Australian school students: 3 . Acne vulgaris. Br J Dermatol 1998;139(5):840-5.

15. Collier CN, Harper JC, Cantrell WC, et al. The prevalence of acne in adults 20 years and older. J Am Acad Dermatol 2008;58(1):56-9.

16. Tan JK, Vasey K, Fung KY. Beliefs and perceptions of patients with acne. J Am Acad Dermatol 2001;44(3):43945.

17. Biswas S, Mondal KK, Saha I, et al. Clinico-epidemiological features of acne vulgaris: a tertiary hospital-based study. Iranian Journal of Dermatology 2010;13(2):37-41.

18. Cunliffe WJ, Holland DB, Clark SM, et al. Comedogenesis: some new aetiological, clinical and therapeutic strategies. Br J Dermatol 2000;142(6):1084-91.

19. Taylor SC, Cook-Bolden F, Rahman Z, et al. Acne vulgaris in skin of color. J Am Acad Dermatol 2002;46(2 suppl):S98-S106.

20. Lucky AW, Biro FM, Hustar GA, et al. Acne vulgaris in premenarcheal girls: an early sign of puberty associated with rising levels of dehydroepiandrosterone. Arch Dermatol 1994;130(3):308-14.

21. Kubba R, Bajaj AK, Thappa DM, et al. Acne in India: factors precipitating or aggravating acne. IAA consensus document. Indian Journal of Dermatology Venereology and Leprology 2009;75(S1):10-11.

22. Ghodsi SZ, Orawa H, Zouboulis CC. Prevalence, severity and severity risk factors of acne in high school pupils: a community-based study. Epidemiology of acne in high school pupils. J Invest Dermatol 2009;129(9):2136-41.

23. Williams M, Cunliffe WJ. Explanation for premenstrual acne. Lancet 1973;10(2):1055-7.

24. Shaw JC. Low-dose adjunctive spironolactone in the treatment of acne in women: a retrospective analysis of 85 consecutively treated patients. J Am Acad Dermatol 2000;43(3):498-502.

25. Stoll S, Shalita AR, Webster GF, et al. The effect of the menstrual cycle on acne. J Am Acad Dermatol 2001;45(6):957-60.

26. Fisher DA. Desideratum dermatologicum-cause and control of premenstrual acne flare. Int J Dermatol 2000;39(5):334-6.

27. Tehrani R, Dharmallingam M. Management of premenstrual acne with cox- 2 inhibitors: a placebo controlled study. Indian J Dermatol Venereol Leprol 2004;70(6):345-8.

28. Walton S, Cunliffe WJ, Keczkes K, et al. Clinical, ultrasound and hormonal markers of androgenicity in acne vulgaris. Br J Dermatol 1995;133(2):249-53.

29. Cibula D, Hill M, Vohradnikova 0 , et al. The role of androgens in determining acne severity in adult women. Br J Dermatol 2000;143(2):399-404.

30. Borgia F, Cannavo S, Guarneri F, et al. Correlation between endocrinological parameters and acne severity in adult women. Acta Dermatol Venereol 2004;84(3): 201-4.

31. Cordain L, Linedeburg S, Hurtado M, et al. Acne vulgaris: a disease of western civilization. Arch Dermatol 2002;138(12):1584-90.

32. Layton AM, Henderson CA, Cunliffe WJ. A clinical evaluation of acne scarring and its incidence. Clin Exp Dermatol 1994;19(4):303-8. 